\title{
Medida y evolución de la movilidad residencial en las áreas metropolitanas españolas
}

\section{Isabel Palomares-Linares}

Universidad de Granada. Departamento de Sociología

ipalomares@ugr.es

\section{José María Feria}

Universidad Pablo de Olavide. Departamento de Geografía, Historia y Filosofía

jmfertor@upo.es

\section{Joaquín Susino}

Universidad de Granada. Departamento de Sociología

jsusino@ugr.es

\section{Resumen}

El objetivo del artículo es cuantificar la evolución de la movilidad residencial a lo largo de tres decenios en las áreas metropolitanas españolas, para lo que hay que superar distintos obstáculos conceptuales y, sobre todo, metodológicos, que constituyen, por tanto, el núcleo del artículo. El primero es la definición de movilidad residencial, que conviene distinguir de la muy afín de migración. El segundo es entrar en los pormenores de la cuantificación de la movilidad residencial, partiendo de la única fuente existente en España que lo permite: el censo. En último lugar, se trata de reconstruir el comportamiento de la movilidad residencial y migratoria en España a dos escalas de análisis: una a nivel nacional y otra a nivel metropolitano. El resultado nos ofrece una evolución, a lo largo de treinta años, de la movilidad residencial, paralela, aunque distinta, de la migratoria.

Palabras clave: áreas metropolitanas; movilidad residencial; migraciones; cambios de vivienda; censos

* Este trabajo es fruto del proyecto coordinado de investigación Movilidad y ciudad real: Dinámicas y cambios territoriales y sociales en España (CSO2014-55780-C3), financiado por el Ministerio de Economía y Competitividad en el marco del Programa Estatal de Fomento de la Investigación Científica y Técnica de Excelencia, Subprograma Estatal de Generación de Conocimiento, convocatoria 2014, modalidad Proyectos de I+D. 
Abstract. Measurement and Evolution of Residential Mobility in Spanish Metropolitan Areas

The goal of this article is to quantify the evolution of residential mobility over three decades in metropolitan areas of Spain, for which it is necessary to overcome different conceptual and, above all, methodological obstacles that constitute the core of the paper. The first task is to define residential mobility, which should be differentiated from the close phenomenon of migration. The second is to delve deeper into the details of the quantification of residential mobility using the only data source in Spain that allows doing so: the census. Lastly, the evolution of residential and migratory mobility in Spain is studied at two different scales of analysis: the national level and the metropolitan level. Thus, we have reconstructed the evolution of residential mobility over thirty years, which runs parallel but different from migrations.

Keywords: metropolitan areas; residential mobility; migrations; housing changes; censuses

\section{Sumario}

\section{Introducción}

2. Necesidad de superar la ambigüedad del concepto de movilidad residencial

3. Fuentes y métodos

4. Contar la movilidad intramunicipal
5. Evolución de la movilidad residencial y migratoria

6. Observaciones finales

Referencias bibliográficas

\section{Introducción}

El estudio de la movilidad residencial puede revestir notables complejidades, como lo demuestra la amplia bibliografía existente y los trabajos que aparecen en este mismo número. Pero, en niveles muy básicos, la falta de acuerdo sobre el uso de esta expresión y las características de las fuentes de datos disponibles hacen que incluso su mera cuantificación para analizar dinámicas temporales sea una tarea difícil. Ese último es, precisamente, el objeto de este primer artículo del presente número monográfico sobre movilidad residencial: la evolución de la movilidad residencial metropolitana en España en el periodo que va desde 1981 hasta 2011.

Aunque aquí solo tratemos algunos países, en todos ellos la mayor parte de los cambios de residencia se producen dentro de una misma unidad urbana. No son, por tanto, migraciones, o, por lo menos, no en el sentido habitual que se da a este concepto. La expresión movilidad residencial no debe, por tanto, confundir la realidad a la que se refiere con la migración. Pero, además, puesto que tratamos de movimientos internos a unidades urbanas, debemos prestar atención a cómo delimitarlas, tanto a efectos de la definición como de la medición de la movilidad residencial y de las migraciones. Empezaremos, por tanto, por discutir el uso que se hace del concepto de movilidad residencial a nivel internacional, con especial referencia al caso español, para, a continuación, hacer una propuesta conceptual que permite distinguirla del término muy relacionado de migración. 
Tras ello, entramos en la parte empírica de este trabajo. Primero presentando las fuentes disponibles y los principales problemas que se presentan cuando queremos comparar una misma fuente a lo largo del tiempo. En nuestro caso, los tres últimos censos. Estos constituyen, además, la única fuente que posibilita analizar su evolución en un periodo tan prolongado. La siguiente sección se dedica a plantear cómo y en qué medida es posible resolver algunos de estos problemas. Aunque la solución es solo parcial, resulta igualmente importante tomar conciencia de las diferencias de medición entre unos periodos y otros, para poder así comparar entre ellos. Por último, se presenta y se discute brevemente acerca de la evolución de la movilidad residencial metropolitana en España a lo largo de tres décadas, teniendo en cuenta las propuestas anteriores.

El interés de este trabajo reside, por una parte en que no hay ningún intento anterior en España para hacer frente a las cuestiones que aquí se abordan sobre la movilidad residencial metropolitana: qué fuentes, cómo utilizarlas, qué hacer para tener series comparables y cómo tratar las diferencias en las fuentes a lo largo de los años. Una tarea que es posible porque, desde hace unos años, contamos, por fin, con delimitaciones de las áreas metropolitanas españolas realizadas con criterios homologables a algunos de los más utilizados a nivel internacional. Algo imprescindible, obvio es subrayarlo, para poder medir y analizar la evolución de este tipo de movilidad en España, a la vez que necesaria para tener un marco sólido de referencia para profundizar en el estudio de la movilidad residencial, ya sea desde planteamientos geográficos, sociológicos o económicos.

\section{Necesidad de superar la ambigüedad del concepto de movilidad residencial}

\subsection{Usos de la expresión movilidad residencial}

La expresión movilidad residencial ha tenido y sigue teniendo dos usos básicos. Por un lado, se emplea en un sentido amplio abarcando todo tipo de desplazamiento que implique un cambio de residencia, cualquiera que sea el ámbito en el que este cambio se produzca. Por otro lado, se emplea en un sentido más restrictivo, referida únicamente a los desplazamientos residenciales que se producen dentro de un ámbito urbano. Ante esta confusión, y sin afán de exhaustividad y mucho menos de realizar la historia de estos usos terminológicos, vamos a repasar algunos ejemplos de ellos.

Muy posiblemente, el primero en el tiempo es el uso más restringido. En el trabajo pionero de Rossi (1955) sobre movilidad residencial, la referencia inicial es el cambio urbano como consecuencia de los cambios de vivienda en el espacio que afectan a barrios y a otras zonas no exclusivamente residenciales. La importancia del estudio de la movilidad residencial se deriva, según el autor, de que es una de las fuerzas principales que subyacen en los cambios urbanos. Ya en ese momento el autor reconoce en la movilidad residencial un concepto central que, desde tiempo atrás, la sociología ha utilizado para 
comprender el modo de vida urbano. Además, con frecuencia, utiliza otra expresión como sinónimo: cambios de vivienda. La referencia son, por tanto, los cambios intraurbanos, que el autor aplica a cuatro barrios concretos de la ciudad de Filadelfia.

Desde una perspectiva económica, las clásicas aportaciones que intentaban explicar la elección residencial utilizando un modelo urbano monocéntrico (Alonso, 1960; Muth, 1961) entiendían la movilidad residencial en estos mismos términos, como movilidad intraurbana, aunque no lo dijeran explícitamente. Pero su principal interés no era la movilidad en sí misma, sino los determinantes de la estructura espacial de las áreas urbanas, como una función de la renta del suelo y los costes de transporte. Según explican Zax y Kain (1991), en las áreas metropolitanas, se produce una interacción entre commutes (desplazamientos cotidianos entre residencia y trabajo), quits (cambios de lugar de trabajo) y moves (cambios de residencia). Los trabajadores han de maximizar la utilidad de la localización residencial en función del lugar de trabajo utilizando quits y moves para ello. Estas últimas constituirían la movilidad residencial.

Este uso de la expresión parece enfrentarse a una utilización del término migración como algo no solo distinto, sino también complementario. Entre todos los cambios de domicilio, la movilidad residencial recoge aquellos que no son migraciones. Pero ello no es siempre así, porque en ocasiones la movilidad residencial aparece como migración intraurbana (Clark, 1982; Cadwallader, 1992). Esta distinción permite a estos autores separar los modelos para explicar uno u otro tipo de movimientos. Es decir, que ambos tipos de desplazamientos son distintos y, por consiguiente, necesitan modelos explicativos diferentes. En este sentido, la movilidad residencial se distingue de la migración porque la primera implica un cambio de residencia y la segunda supone un cambio simultáneo de trabajo y residencia (Zax, 1994). En el diccionario de UISSP (1985), la expresión movilidad residencial parece estar clara: sería equivalente a movilidad local, interna a un área urbana. Algo así como los cambios de domicilio locales. Se presenta, además, como excluyente de las migraciones.

De esta forma, la movilidad residencial se distingue de manera clara de la migración interurbana. En este sentido, es utilizada por numerosos autores desde los años sesenta, sobre la base en cualquier caso de que, por local, deben entenderse ciudades metropolitanas (Quigley y Weinberg, 1977; Short, 1978). Pero no solo por los ámbitos en los que se produce (la movilidad es interna a una unidad funcional, mientras la migración supone un movimiento entre unidades diferentes), sino también por las características de sus protagonistas (Geist y McManus, 2008) o los determinantes de las mismas (Clark y Onaka, 1983; Cadwallader, 1992; Clark y Huang, 2003). No es difícil encontrar investigaciones hasta nuestros días que analicen diferentes aspectos de la movilidad residencial utilizando esta aproximación conceptual (Clark et al., 2006; Howley, 2009; Clark, 2013).

No obstante, otras aproximaciones encuentran dificultades para mantener esta distinción, sobre todo por razones de orden empírico, en cuanto a la obtención de datos o a la comparación entre realidades socioterritoriales dife- 
rentes. La dificultad, sobre todo en estudios comparados entre países, de estudiar la movilidad a partir de referencias administrativas ha hecho que algunos investigadores pretendan sortearla recurriendo a la distancia de la migración (Long et al., 1988). Esta línea de investigación parte del mismo supuesto de que los cambios residenciales a larga distancia están movidos por factores y motivos diferentes que los cambios a corta distancia, constatándolo empíricamente. Pero entonces ambos tipos de cambios reciben frecuentemente la denominación de migraciones: de corta distancia frente a larga distancia (Niedomysl, 2011; Niedomysl y Fransson, 2014), cuando partes de las migraciones de corta distancia se sitúan en el terreno de la movilidad residencial. Por esta razón, otros autores siguen distinguiendo «[...] entre movilidad residencial local, probablemente asociada con las transiciones del curso de la vida, y migración fuera del mercado local de trabajo, que puede ser impulsada más por el empleo y otras consideraciones socioeconómicas» (Tolbert et al., 2009: 24). Porque, en último extremo, lo que diferencia unos tipos de movimientos de otros no es la distancia en sí misma, sino que se produzcan o no dentro de un mismo mercado de trabajo.

Parte de la confusión proviene, por tanto, del uso de la expresión intraurban migration para referirse a lo que la UISSP (1985) llamaba movilidad local o residencial. Algunos de los clásicos del estudio de la movilidad residencial ya utilizaban esta expresión (Brown y Moore, 1970). Es algo especialmente frecuente en la tradición británica (Halfacree et al., 1992; Jones et al., 2004), aunque también es utilizada en otros contextos geográficos (Weinberg, 1979; Berman y Eaglstein, 1988; Burnley, 1996; Wu, 2006). Incluso se da el caso de algunos autores que utilizan expresiones distintas — movilidad residencial o migración intraurbana - en diferentes trabajos (Smith et al., 1979).

Asimismo, en otros contextos, es frecuente el uso del término movilidad residencial de forma más general, englobando movilidad intraurbana y migraciones. Pasa en la tradición francesa, al menos reciente (Debrand y Taffin, 2005; Shon, 2005; Donzeau y Shon, 2009). Pero algunos textos, aunque estén encabezados por la expresión movilidad residencial, empiezan hablando de migraciones, lo que lleva al lector a pensar que ambas son equivalentes (Courgeau y Meron, 1995; Gobillon, 2001). De este uso parece haberse hecho eco Demopaedia (2017), página web de la misma institución que antes daba una definición más precisa (IUSSP, 1985).

En España, a finales de la década de 1980, algunos autores hablaban de movilidad residencial, tanto en la geografía (Jiménez Blasco, 1988, que insiste en utilizar una expresión más amplia: movilidad residencial intraurbana) como en la psicología ambiental (Aragonés y Amérigo, 1987, que utilizan la expresión en su significado amplio, pues en varios momentos distinguen entre la intraurbana y la interurbana o migratoria). Pero no es hasta mediados de la década de 1990 cuando su uso se difunde. No obstante, el significado no parece estar suficientemente fijado: varía entre el concepto amplio y el restringido. La que quizá sea la primera tesis doctoral dedicada específicamente al tema (Módenes, 1998) hace un uso más bien amplio, como en otros textos poste- 
riores del mismo y otros autores (Módenes, 2000; López Gay, 2003), aunque no siempre es así. En otra tesis sobre el mismo objeto, el uso es el restringido (Susino, 2003). Y así es usado por otros autores para referirse a una movilidad específicamente intrametropolitana (Miralles, Donat y Barnada, 2007). También en Latinoamérica es frecuente el uso en sentido restringido, como movilidad residencial intraurbana (Duhau, 2003). En el campo de la economía, Arévalo, Ferrero, Otero y de Uña (2008) utilizan la expresión movilidad residencial en términos generales, para referirse a todo cambio de vivienda, sea o no una migración, aunque realmente no le dedican atención a esta cuestión. En otras ocasiones se utiliza la expresión movilidad residencial metropolitana para referirse a los cambios entre municipios dentro de un área metropolitana, a los que también se suele llamar migraciones residenciales (Bayona y Pujadas, 2014) o migraciones intrametropolitanas (García Coll et al., 2016).

Es posible que por todas estas razones tantos autores, entre los cuales los de este mismo artículo, se vean en la necesidad de añadir a movilidad residencial el adjetivo de intraurbana, para aclarar a qué se refieren aunque en otra situación no tendría por qué ser necesario.

\subsection{De la definición a la medida de la movilidad residencial}

Pero si la definición y uso del concepto de movilidad residencial presenta ambigüedades, las dificultades aumentan cuando se trata de medirla. Por dos razones: (i) por las características de las escasas fuentes disponibles y (ii) por la unidad territorial que esas fuentes toman de referencia. Aunque en términos conceptuales la movilidad y las migraciones estén diferenciadas, los autores han optado por múltiples formas de medirla, en ocasiones contradictorias entre sí, que han llevado a diferencias significativas en su estimación (White y Mueser, 1988). Estas diferencias son producto de las múltiples estrategias desarrolladas para sortear las restricciones provenientes de las fuentes y conseguir definir unidades territoriales coherentes con los modelos teóricos o simplemente con la disponibilidad de datos.

En muchos trabajos se opta por aceptar las limitaciones de las fuentes, en la medida en que sus objetivos se adecuan más o menos a los datos disponibles. Entre estos encontramos, por un lado, los que limitan el análisis de la movilidad a aquella que se produce dentro de las unidades administrativas, ya sean condados como en el caso norteamericano (US Census Boureau, 2003), o municipios como en el caso español. Por otro, aquellos que, partiendo del hecho de que la mayoría de movimientos que se producen en el seno de una unidad administrativa intermedia (como puede ser la provincia en el caso espanol) son efectivamente movilidad residencial, deciden analizar como tal todos los cambios dentro de las mismas (López-Gay y Recaño, 2008; FernándezTroyano, 2010).

Sin embargo, en otros casos, entre los que contamos el grueso de los estudios más recientes, se opta por construir unidades funcionales en las que la movilidad es criterio definitorio de las mismas. Uno de estos tipos de unida- 
des son las áreas metropolitanas, cuyo uso está muy generalizado desde hace décadas en los Estados Unidos (Dieleman et al., 2000). Otro tipo de unidades son los mercados locales de trabajo o zonas de commuting, con gran tradición en el mundo anglosajón y muy extendido en los análisis de la movilidad de corte más económico (Long et al., 1988; Gibbs, 1994; Henley, 1998; Tolbert et al., 2009).

En el caso español, al igual que en otros países europeos, el uso de las unidades funcionales es aún incipiente, por la simple razón de que las delimitaciones de tales unidades no están institucionalizadas y, por tanto, los organismos estadísticos no las utilizan para la tabulación normal de los datos que producen. Recientemente se han hecho propuestas para el caso español, pero limitadas a pocas áreas o periodos pequeños (Casado, 2000; Susino, 2003; Feria, 2008, 2015). De ahí el interés de nuestro intento en este artículo, porque por primera vez se cuantifica la evolución de la movilidad metropolitana en todas las áreas españolas y durante un periodo largo de tiempo.

No obstante, la posibilidad de construir unidades funcionales que tengan sentido, es decir, que delimiten una ciudad real o, más en general, un mercado unificado de trabajo y de vivienda, está supeditada a las posibilidades de las fuentes utilizadas. Hay que tener en cuenta que lo que no se defina como movilidad residencial será, según esto, migración. Por tanto, las definiciones de ambos conceptos están íntimamente ligadas.

Debemos recordar aquí la propuesta de Courgeau (1988) sobre la migración entendida como cambio en el espacio de vida: el espacio en el que transcurre la existencia cotidiana, usual, de los individuos de una población. Según esta definición, serían migraciones los movimientos que supongan un cambio en el espacio de vida, no siéndolo los demás. Pero, para que esta aproximación sea operativa, debe entenderse el espacio de vida en términos colectivos, para el conjunto de una comunidad urbana. Y, desde luego, para todos los miembros de la misma unidad familiar, cualesquiera sean las actividades que conformen sus espacios de vida individuales Lo que importa, en este caso, es que el cambio de vivienda no tenga por qué implicar una modificación en el espacio de vida o de la actividad que en mayor medida lo estructura: el lugar de trabajo. Según esto, la movilidad residencial es más bien un cambio de domicilio dentro de una misma unidad territorial funcional, un espacio de vida colectivo, y esta unidad se identifica por constituir un mercado unificado de trabajo y de vivienda. La forma urbana por antonomasia que los conjuga es el área metropolitana (Feria, 2010).

De todo lo que hemos visto, se deduce que los movimientos de cambio de residencia pueden clasificarse en función de dos dimensiones: el ámbito en el que se produce el cambio y la unidad territorial de referencia de los datos disponibles sobre los cambios. Combinando ambas dimensiones, podemos clasificar los cambios de residencia como se indica en el cuadro 1.

Por lo que se refiere al ámbito en el que se produce el cambio de residencia, este puede ser urbano o interurbano. Por lo que respecta al tipo de unidad territorial que se toma de referencia para medir y cuantificar los cambios, 
esta puede ser la unidad administrativa mínima para la que se recopilan estos datos, el municipio, o la unidad funcional que corresponde a la ciudad realmente vivida, que aunque en muchos casos, los de menor desarrollo urbano, sigue siendo municipal, en muchos otros ha llegado a ser metropolitana. La combinación de ambas dimensiones da lugar a cuatro posibles tipos de movimiento.

Si tomamos como unidad de referencia el municipio, los movimientos entre ellos son migraciones en sentido estadístico. Es decir, aquellas que normalmente clasifican como tales los organismos de producción estadística. Frente a ellas, el resto de movimientos son cambios de domicilio, tal como normalmente son llamados por los mismos organismos (el INE en algún censo o en la ESD de 1991, por ejemplo) o cambios de vivienda, cuando tienen lugar dentro de un municipio, la unidad territorial más pequeña para la que se recaba este tipo de datos en España.

Si tomamos como referencia unidades urbanas funcionales, lo que significa considerar no solo municipios individualizados, sino también áreas metropolitanas compuestas por varios municipios, tenemos dos tipos de movimientos. Por un lado, las migraciones entendidas como cambios en el espacio de vida colectivo en el que se desarrolla la vida cotidiana de sus habitantes (las áreas metropolitanas). Por otro, la movilidad residencial como cambio intraurbano, ya sea dentro de una misma área metropolitana, ya sea interno a los municipios que no pertenecen a estas áreas funcionales supramunicipales. Ambos esquemas funcionan individualmente: o se opta por uno o por otro. Todo depende de la unidad territorial que sirva de referencia para analizar los cambios.

Por eso proponemos limitar el uso de la expresión movilidad residencial para referirnos específicamente a los cambios intraurbanos, teniendo en cuenta la extensión del fenómeno metropolitano. Si se quiere evitar cualquier confusión, a esta expresión se le puede añadir un simple adjetivo: movilidad residencial intraurbana. Lo que queda fuera de esta definición es la migración, que no incluye la totalidad de ellas en sentido estadístico, solo la que se produce entre unidades urbanas diferentes. Para referirnos al conjunto de todos los cambios de residencia, podemos utilizar una expresión que evita cualquier malentendido: movilidad residencial y migratoria.

Cuadro 1. Esquema conceptual de la movilidad residencial y migratoria según tipos de unidades territoriales de referencia

\begin{tabular}{|c|c|c|c|}
\hline & & \multicolumn{2}{|c|}{ Ámbito de la movilidad } \\
\hline & & Intraurbano & Interurbano \\
\hline \multirow{2}{*}{$\begin{array}{l}\text { Unidad territorial } \\
\text { de referencia }\end{array}$} & Administrativa (municipio) & Cambio de domicilio & $\begin{array}{l}\text { Migración en sentido } \\
\text { estadístico }\end{array}$ \\
\hline & $\begin{array}{l}\text { Funcional (área metropolitana } \\
\text { y municipio no metropolitano) }\end{array}$ & Movilidad residencial & $\begin{array}{l}\text { Migración como } \\
\text { cambio en el espacio } \\
\text { de vida }\end{array}$ \\
\hline
\end{tabular}

Fuente: elaboración propia. 


\section{Fuentes y métodos}

Esta definición de movilidad residencial plantea dos tipos de problemas a resolver: la delimitación del universo metropolitano y los datos a utilizar. Hay que señalar que los límites municipales son una imposición de las estadísticas, de cómo se construyen y de cómo se explotan en España. Del mismo modo que las áreas metropolitanas se forman por agregación de municipios distintos, dentro de algunos municipios -metropolitanos o no-, existen sistemas de asentamientos complejos formados por varios núcleos o entidades de población que funcionan como unidades urbanas distintas. Aunque esto no es posible tenerlo en cuenta, es oportuno saber que este fenómeno afecta, fuera de las áreas metropolitanas, a un volumen de población y de movimientos relativamente pequeño. Pero, antes de tratar estos problemas, es necesario elegir la fuente de datos más adecuada.

En España, para medir la movilidad residencial, la única fuente que ofrece datos de movimientos entre municipios, como también dentro de los municipios, es el censo de población. Además, no todos los censos permiten cuantificar la movilidad intramunicipal, únicamente los tres últimos, que son, por tanto, los utilizados en este análisis.

Existen otras fuentes que cuantifican las migraciones intermunicipales. La más importante es la constituida por las estadísticas de variaciones residenciales. Estas podrían también ofrecer datos sobre los cambios de domicilio intramunicipales, pero no son explotadas por el INE. Algunos grandes municipios, como Madrid o Barcelona, ofrecen estas explotaciones, pero eso no puede tomarse como norma, sino como excepción. Por eso hay algún estudio que utiliza estas fuentes (Bayona y Pujadas, 2010), pero aún así se enfrentan a dificultades para desarrollarlos a escala metropolitana, porque no todos los municipios pertenecientes al área metropolitana hacen lo mismo. Además, aunque el INE explotase con carácter general los movimientos intramunicipales derivados de las altas y bajas del padrón de habitantes, esta fuente tropezaría con una notable limitación: permitiría cuantificar la movilidad pero profundizar muy poco en los rasgos distintivos de quienes la protagonizan, puesto que el padrón se limita a las características meramente demográficas, con lo que carece de información sobre las características sociales de los individuos estudiados.

La movilidad residencial se puede analizar a través de encuestas, pero estas deberían contemplar en su codificación las delimitaciones de las áreas metropolitanas, lo que en España no es común, porque no existe una delimitación institucionalizada a efectos estadísticos, como sí existe en otros lugares. Por esta razón, la Encuesta Sociodemográfica de 1991 permite analizar los movimientos intramunicipales, pero no los de escala intermedia entre los municipales y los provinciales, los metropolitanos (Zamora y Serrano, 2000; Susino, 2003). La mayoría de encuestas del INE o de otros organismos, como los barómetros del CIS, clasifican los cuestionarios por el tamaño del municipio de residencia, pero obvian su pertenencia o no a una realidad metropolitana (o no está actualizada), con lo que prima lo administrativo sobre lo funcional. 
No obstante, algunas encuestas permiten conocer ambos tipos de movimientos, los intramunicipales e los intermunicipales, como la encuesta metropolitana de Barcelona (Miralles Guasch y Tulla, 2012). Los autores de este trabajo realizaron una encuesta en el área metropolitana de Granada, para el Ayuntamiento de la capital, que permite estudiar la totalidad de la movilidad metropolitana en un periodo de diez años, pero, como suele ocurrir en este tipo de estudios, los datos no son de libre disposición pública, aunque el organismo al que pertenecen haya permitido su explotación a los investigadores responsables del estudio (Susino y Palomares-Linares, 2013; Clark et al., 2015). En todo caso, se trata de operaciones puntuales con las limitaciones propias de las muestras y solo para áreas concretas, no para el universo metropolitano español.

Aunque los tres últimos censos de población permiten analizar movimientos intramunicipales e intermunicipales, la tarea tropieza con varios obstáculos. En primer lugar, el INE no tabula los datos para las áreas metropolitanas y es necesario agregarlos a partir de las matrices de movilidad intramunicipal e intermunicipal. Pero estas matrices no son públicas, por ello resulta indispensable solicitar una explotación específica al INE, que, lógicamente, está afectada por las limitaciones que impone la preservación del secreto estadístico y, en el caso del censo de 2011, por las estimaciones derivadas de su carácter muestral.

La primera cuestión es tener una delimitación de áreas metropolitanas basada en criterios homogéneos y asimilables a las clasificaciones más consolidadas internacionalmente (Feria, 2004). En España, contamos con diversos acercamientos a partir de la década de 1960 (De Esteban, 1981). De las más recientes no todas cumplen los requisitos imprescindibles. La realizada por el Ministerio de Vivienda y posteriormente Fomento, para el atlas urbano de España (Ministerio de Fomento, 2016) presenta el problema de que los criterios de delimitación no están bien explicitados y, por tanto, no dan resultados fácilmente replicables, con lo que incumple una condición básica del trabajo científico. Otras delimitaciones se basan en la movilidad cotidiana por razón de trabajo (Roca et al., 2012; AUDES, 2016), pero la que desarrolla de manera más exhaustiva el procedimiento y ofrece resultados más consistentes es la realizada por el proyecto de investigación MoviTra (Feria, 2008; Feria y Martínez, 2016). Por tanto, aquí nos basamos en estos trabajos, a los que remitimos para profundizar en el método y en los resultados de tal delimitación (figura 1). Aunque, recientemente, el INE (2016) ha elaborado una propuesta de lo que denomina áreas urbanas funcionales para la publicación de indicadores dentro del programa europeo Urban Audit y basada en la metodología desarrollada en el proyecto de investigación. Con resultados parecidos, pero también con ciertas inconsistencias y debilidades, además de que, entre los indicadores publicados, no se encuentra ninguno relativo a movilidad residencial.

Efectivamente y tal como se ha señalado, para el estudio de la movilidad intramunicipal e intermunicipal, los censos constituyen la fuente más consistente, pero su uso presenta varias dificultades en cuanto a los aspectos siguientes: 
Figura 1. Mapa de las áreas metropolitanas españolas en 2011

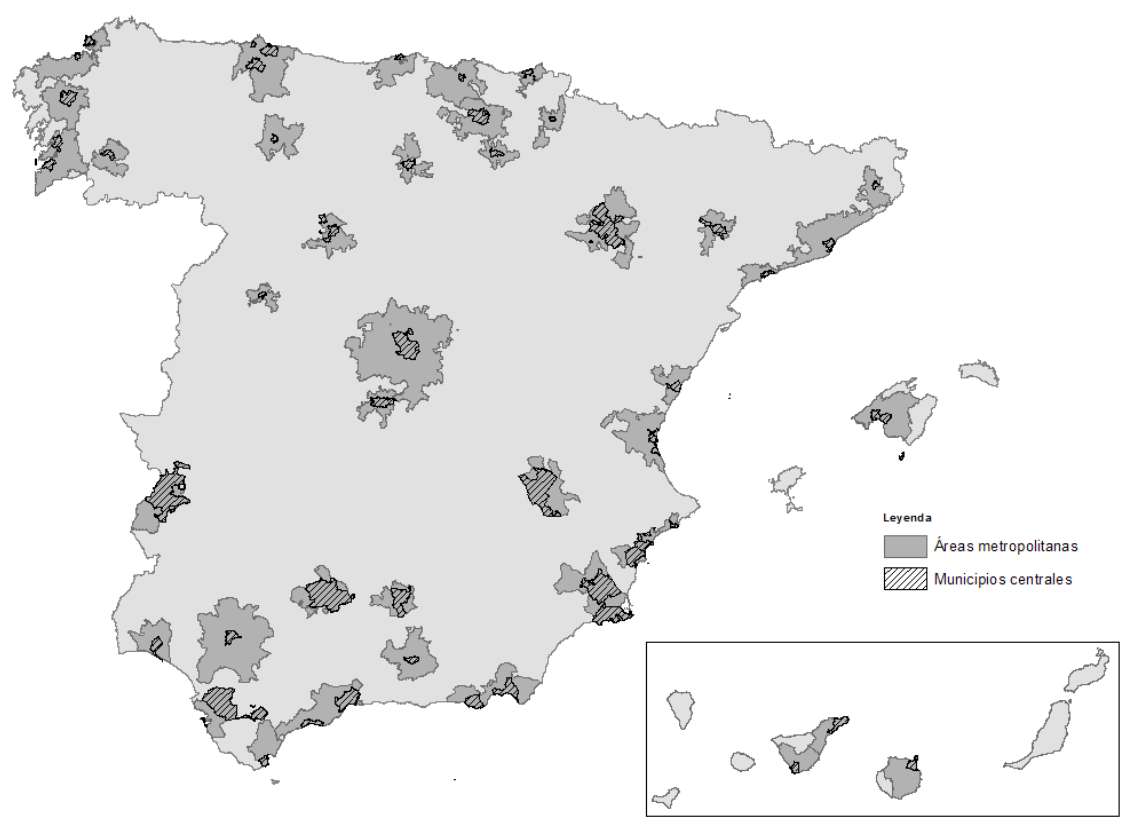

Fuente: elaboración propia basada en Feria y Martínez (2016).

1. La población de referencia.

2. Los periodos a analizar en relación con las preguntas censales.

3. El hecho de que las preguntas que permiten la cuantificación de la movilidad intramunicipal han cambiado en los tres últimos censos.

1. En cuanto a la población de referencia para medir la movilidad residencial, puede venir constituida por el universo completo de toda la población residente en España en el momento en que se hace cada censo o solo por la población que vive en domicilios familiares. El censo de 1991 permite estudiar la movilidad de ambas poblaciones, pero los posteriores exclusivamente la segunda, por lo que la única opción posible para comparar entre censos es restringir el estudio a la movilidad de la población que habita en viviendas familiares. Pero esto significa que, por una parte, no se tienen en cuenta los movimientos entre viviendas familiares en origen y colectivas en destino (aunque sí los movimientos inversos) y, por otra, que, al contar los censos de distinta forma la población que vive en viviendas colectivas, se ven afectadas las cifras de movimientos protagonizados por los que allí residen o han residido.

2. En lo que se refiere a los periodos de análisis, hay que decidir si resulta más conveniente medir la movilidad a diez años o a un año. Limitando por el 
momento este debate a las migraciones, los tres censos contienen una pregunta idéntica sobre el lugar de residencia en el momento en que se realizó el censo anterior (aunque el periodo al que se refiere la pregunta no siempre es de diez años exactos). Los tres censos también incluyen una pregunta sobre el año de llegada al municipio de residencia. Además, los censos de 1991 y de 2011 preguntan por el lugar de residencia un año antes, pero no el de 2001, por lo que a estos efectos habría que utilizar la pregunta sobre la residencia anterior y el último año de llegada ${ }^{1}$. Como se explica en otro lugar (Susino, 2011), la pregunta por el lugar de residencia a una fecha fija tiene ventajas sobre la cuestión sobre la residencia anterior. Esta última cambia entre los censos y, además, dificulta la estimación de la movilidad intramunicipal, especialmente en el censo de 2001, por lo que no podemos utilizarla a los efectos aquí planteados. En este trabajo, por tanto, nos centramos en los problemas de medición de la movilidad en relación con el censo anterior, que es la mejor cuando estamos interesados en las tendencias y en los cambios más estructurales de la movilidad y en su evolución en el largo plazo.

3. El último aspecto afecta a las preguntas que permiten cuantificar la movilidad. Hay que advertir, en todo caso, que los cuestionarios censales se refieren a los móviles, al número de personas que tienen tal condición, no a los movimientos que han hecho durante el periodo considerado. La cuestión sobre el lugar de residencia en el momento de realizar el censo anterior está formulada de idéntica manera en los tres censos en el caso de los cambios entre municipios, pero no hay homogeneidad para la forma en que podemos cuan-

Cuadro 2. Dificultades para medir la movilidad residencial en tres censos sucesivos

\begin{tabular}{|c|c|c|}
\hline A qué se refiere & De qué tipo es & Cómo la tratan los censos \\
\hline $\begin{array}{l}\text { 1. Población } \\
\text { de referencia }\end{array}$ & $\begin{array}{l}\text { Distinto tratamiento } \\
\text { de la población residente } \\
\text { en viviendas colectivas }\end{array}$ & $\begin{array}{l}\text { 1991: «teóricamente», residentes efectivos } \\
\text { 2001: solo recoge empadronados } \\
\text { 2011: recoge empadronados y residentes efectivos }\end{array}$ \\
\hline $\begin{array}{l}\text { 2. Periodo asociado } \\
\text { al tipo de pregunta }\end{array}$ & $\begin{array}{l}\text { Lugar de residencia } \\
\text { en el censo anterior }\end{array}$ & $\begin{array}{l}\text { 1991: diez años antes } \\
\text { 2001: diez años y ocho meses antes } \\
\text { 2011: diez años antes }\end{array}$ \\
\hline & $\begin{array}{l}\text { Lugar de residencia } \\
\text { en el último año }\end{array}$ & $\begin{array}{l}\text { 1991: un año antes } \\
\text { 2001: Ilegada en el último año (diez meses) } \\
\text { 2011: un año antes }\end{array}$ \\
\hline $\begin{array}{l}\text { 3. Movilidad } \\
\text { intramunicipal }\end{array}$ & $\begin{array}{l}\text { Tres conjuntos de } \\
\text { preguntas diferentes para } \\
\text { su estimación }\end{array}$ & $\begin{array}{l}\text { 1991: igual que los cambios de municipio } \\
\text { 2001: Ilegada a la vivienda del hogar } \\
\text { 2011: Ilegada a la vivienda del individuo }\end{array}$ \\
\hline
\end{tabular}

Fuente: elaboración propia.

1. El censo de 1991 también incluye una pregunta sobre el lugar de residencia cinco años antes, pero no la tenemos en cuenta, porque no se ha vuelto a repetir en censos posteriores. 
tificar la movilidad intramunicipal, porque en los tres censos hay tres modos distintos de acceder a estos cambios de domicilio.

Debemos, por tanto, analizar detenidamente los tres problemas planteados que se resumen en el cuadro 2, en busca de posibles soluciones.

\section{Contar la movilidad intramunicipal}

\subsection{La población que vive en viviendas colectivas}

La base común de todos los censos con los que hemos trabajado es la movilidad de quienes habitan en viviendas familiares, convencionales. Como esta condición se refiere a la situación cuando se realiza el censo, los movimientos de viviendas colectivas a familiares aparecerán recogidos junto a los demás movimientos, sin poder separarlos, ya que no consta el tipo de vivienda anterior. Sin embargo, no ocurre lo mismo con quienes se trasladan a establecimientos colectivos.

Los últimos censos (con la excepción del realizado en 1991²) no disponen de información acerca de la movilidad hacia este tipo de residencias, por lo que solo podemos estimar una medida aproximada a partir de los porcentajes de personas que viven en estos establecimientos, ya sean militares, religiosos, penitenciarios, sanitarios, hoteleros, etc. y, sobre todo, de mayores. Pero las formas en que medimos la movilidad a través de los censos están condicionadas por los métodos de recogida y explotación de los datos en este tipo de establecimientos. Esta metodología ha variado, lo que ha dificultado las comparaciones entre los periodos.

En 1991, se censó a toda la población residente en establecimientos colectivos, por lo que es el único censo que teóricamente no plantea inconvenientes, aunque, por el análisis de algunos datos ${ }^{3}$, resulta obvio que el criterio seguido se parece más al de empadronamiento que al de residencia efectiva.

En 2001, por cuestiones de índole económica, como se especifica en el proyecto censal (INE, 2001), se decidió no encuestar a los residentes en establecimientos colectivos, a los que únicamente se les envió la renovación del padrón a los ya empadronados en los centros. En 2011, se retoma la idea de entrevistar a los residentes efectivos en establecimientos colectivos, independientemente de su situación de empadronamiento. Por tanto, en teoría, bien la cifra de censados, bien la de empadronados, permitiría la comparación con los censos anteriores.

A partir de la información accesible a través de la página web del INE, sabemos que, en 1991, la movilidad migratoria y residencial de los que

2. En el cuestionario de 2011 destinado a personas residentes en establecimientos colectivos, se incluye una pregunta por el lugar de residencia un año antes (no así en relación con el censo anterior), pero no hemos encontrado ninguna publicación o aplicación que permita explotarla.

3. Por ejemplo, este censo solo recoge en instituciones penitenciarias el equivalente al $11 \%$ de la población reclusa, según se deriva de las estadísticas del Ministerio del Interior. 
Cuadro 3. Personas en establecimientos colectivos sobre el total y variación intercensal

\begin{tabular}{llcccc}
\hline & Total & 65 años o más & $\begin{array}{c}\text { Porcentaje de } \\
65 \text { años o más }\end{array}$ & $\begin{array}{c}\text { En residencias } \\
\text { de mayores }\end{array}$ \\
\hline 1991 & Total censado & 254.271 & 141.110 & $55 \%$ & 108.448 \\
2001 & Total empadronado & 251.510 & 161.580 & $64 \%$ & 96.338 \\
2011 & Total censado & 444.101 & 290.021 & $65 \%$ & 270.286 \\
& Del que empadronado & 241.187 & & & 166.485 \\
\hline
\end{tabular}

Fuente: elaboración propia a partir de los censos de 1991, 2001 y 2011, www.ine.es

vivían en establecimientos colectivos alcanzó el 61\%, en comparación con el lugar de residencia en 1981 . Se trata de un porcentaje mucho mayor que en la población residente en viviendas convencionales, que era del $32 \%$. Es decir, gran parte de quienes vivían en establecimientos colectivos habían llegado en los diez años anteriores provenientes de otros municipios o de otro domicilio en el mismo municipio. Este porcentaje es aún mayor en el caso de quienes vivían en residencias de mayores, puesto que alcanzó el 74\%. Como la proporción que representan los mayores y los que viven en residencias de mayores era más alta en los censos de 2001 y 2011 (ver cuadro 3), es de suponer que el porcentaje de móviles en el colectivo de residentes en viviendas colectivas habrá aumentado. Una buena parte de ellos son, por tanto, móviles.

Por consiguiente, al considerar únicamente la movilidad residencial y migratoria de los que habitan en domicilios convencionales, subestimamos la movilidad total de la población. Primero, porque incluimos como sedentarios a quienes viven en estos establecimientos, pero que no han variado su situación de empadronamiento. Segundo, porque, cuando calculamos tasas o proporciones, se ven afectados no solo los numeradores (móviles), sino también los denominadores (población susceptible de moverse). Efectivamente, en 1991, las personas que residen en establecimientos colectivos se descuentan de la población que habita en viviendas convencionales (población con la que se construyen las tasas); pero en 2001 y 2011 solo se descuenta la población empadronada en estos centros, no la que efectivamente vive en ellos (INE, 2001; INE, 2011).

El error es irrelevante cuando tratamos de la movilidad de toda la población, puesto que la proporción de quienes viven en establecimientos colectivos es muy pequeña (cuadro 4), pero es importante cuando se estudia la movilidad de determinados colectivos o grupos de edad, como son las personas mayores (Palomares-Linares, 2014). No solamente porque el $46 \%$ de los que viven en estos establecimientos no está empadronado allí, sino porque una parte muy importante está formada por ancianos que se han trasladado recientemente (últimos diez años), como reflejaba el censo de 1991. Por tanto, la movilidad de los mayores está subestimada, porque no podemos contar estos desplazamientos y porque muchos de los desplazados siguen apareciendo como si no se hubiesen movido de su domicilio convencional. En un contexto envejecido en 
Cuadro 4. Distribución de la población censada en viviendas convencionales y empadronada en establecimientos colectivos en los tres últimos censos

\begin{tabular}{lrrr}
\hline & \multicolumn{1}{c}{1991} & \multicolumn{1}{c}{2001} & \multicolumn{1}{c}{2011} \\
\hline Población total & 38.872 .268 & 40.847 .371 & 46.815 .916 \\
Población en viviendas familiares/principales & 38.617 .997 & 40.595 .861 & 46.574 .730 \\
Población en establecimientos colectivos & 254.271 & 251.510 & 241.187 \\
Porcentaje en establecimientos colectivos & $0,7 \%$ & $0,6 \%$ & $0,5 \%$ \\
\hline
\end{tabular}

Fuente: elaboración propia a partir de los censos de 1991, 2001 y 2011, www.ine.es

el que el internamiento gana peso como opción residencial, obviar la importancia de estos movimientos resulta difícil de justificar.

\subsection{Los periodos intercensales en el análisis de la movilidad}

Respecto a los periodos intercensales, el problema se sitúa en el censo de 2001, por la simple razón de que es más largo: la fecha de referencia de dicho censo es el 1 de noviembre, cuando la del censo de 1991 es el 1 de marzo. La cuestión a resolver es cuántos movimientos pueden achacarse a los ocho meses adicionales contabilizados en este periodo frente a los periodos intercensales de los dos censos restantes, que son diez años exactos.

Una solución rápida pasa por dividir el periodo completo entre su duración (en años) para estimar la media anual. Seguramente, en muchos casos eso pueda resultar suficiente, pero la pregunta que estamos utilizando "deforma» el tiempo. Al preguntar por el lugar de residencia en una fecha fija anterior, no se obtienen todos los cambios, sino el que ha dado lugar a la residencia actual. Los cambios anteriores a este último movimiento son desconocidos. La pregunta, por tanto, tiende a retener las modificaciones más recientes, mientras desaparecen las más antiguas si fueron seguidas de otra posterior.

Figura 2. Evolución de las migraciones según el lugar de residencia en el censo anterior y el año de llegada al municipio en tres censos sucesivos

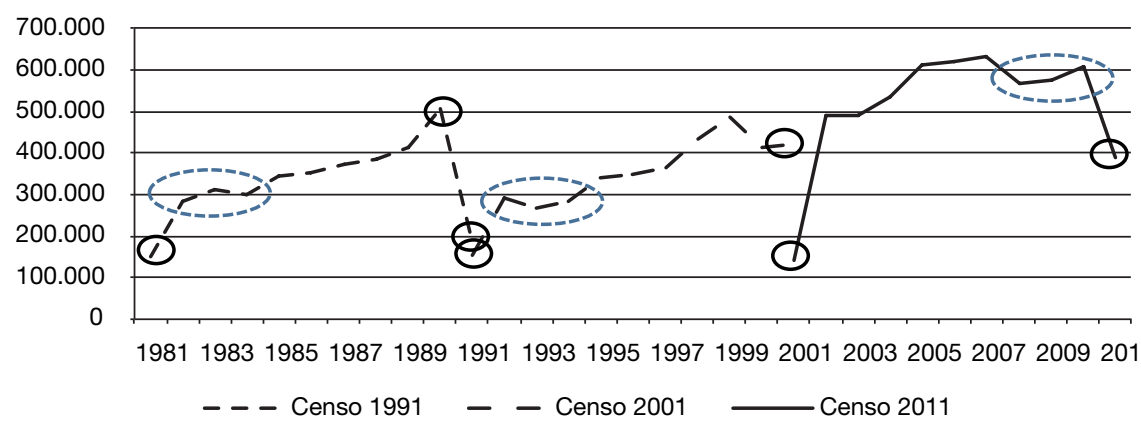

Fuente: elaboración propia a partir de los censos de 1991, 2001 y 2011, microdatos, www.ine.es 
Figura 3. Año de llegada al municipio según el censo de 2011

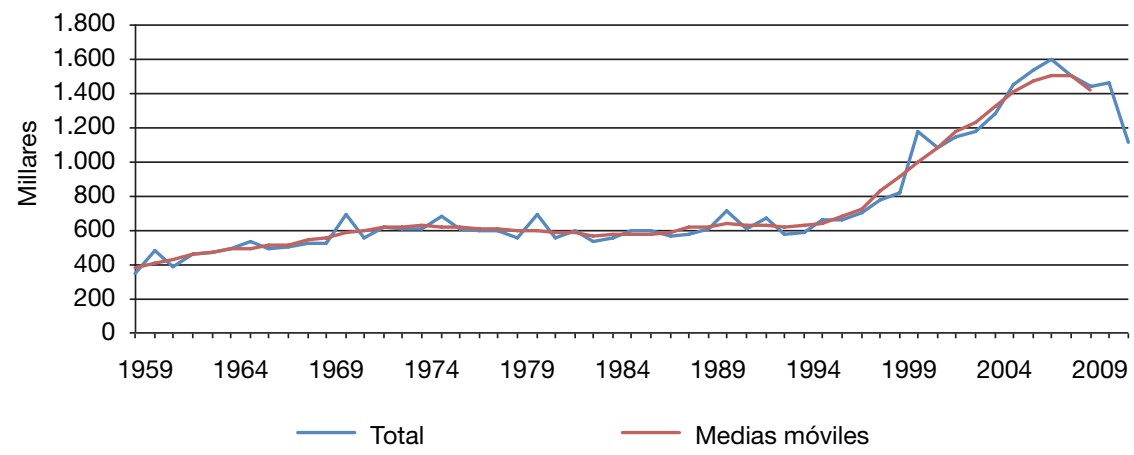

Fuente: elaboración propia a partir del censo de 2011, microdatos, www.ine.es

Como puede observarse (figura 2), si se cruza el año de llegada al municipio con el lugar de residencia diez años antes, las tres líneas correspondientes a los tres censos recogen una tendencia general a estimar mejor las modificaciones más recientes a la realización de cada censo, en detrimento de los más antiguos. Pero esta tendencia evolutiva parece romperse durante las tres crisis de empleo sufridas durante estas décadas (De la Fuente, 2016). No obstante, siguen presentes tres anomalías: la excepcionalmente alta movilidad de 1990, la baja de 2000 en comparación con los años anterior y posterior y la también más alta en 2010 en comparación con los años que lo preceden y lo siguen. Son las fechas más cercanas a la realización de los censos. Algunas de estas anomalías pueden explicarse por la tendencia a redondear las cifras acabadas en cero y, en menor medida, en cinco, cuando las preguntas exigen demasiado de la memoria de los encuestados (figura 3, referida al censo de 2011).

En resumen, se observa un efecto de «deformación» del tiempo sobre la serie que hace que haya más móviles cuanto más cercano al momento censal es el año considerado. Y todo ello sin tener en cuenta las imprecisiones y los problemas de memoria que acarrean preguntas de este tipo. Nuestros análisis muestran que este efecto puede estar entre el $4 \%$ anual de crecimiento del número de migrantes, si tenemos en cuenta todos los años, y el $8 \%$, si exceptuamos los años anómalos y los periodos de crisis del empleo. Los movimientos correspondientes a los ocho meses de más que tiene el segundo periodo intercensal (1991-2001) serían aproximadamente un 3,2\% del total de los registrados en el censo de $2001^{4}$, cifra que prácticamente es la mitad del porcentaje que representan esos ocho meses sobre el total de 128 del periodo intercensal completo. Para comparar el número de móviles del censo de 2001 con los otros dos habría, por tanto, que deducir un 3,2\%.

4. Algo menos de 8/10 del total de movimientos de 1991, ya que el periodo intercensal 19912001 solo comprende diez meses de ese año). 
En el caso de la cuestión sobre la movilidad existente en el año anterior al censo, de nuevo la situación en el 2001 es distinta a la de los otros dos. Mientras que, en 1991 y 2011 se pregunta por la situación de residencia un año antes, en 2001 la cuestión se plantea en referencia a la residencia anterior y no a la de hace un año, por lo que hay que basarse en las variables sobre el año de llegada - tanto al municipio como a la vivienda - para construir la movilidad anual. Puesto que el censo de 2001 tiene como fecha de referencia el 1 de noviembre, los datos del último año solo comprenden diez meses. En este caso, creemos justificado añadir los dos meses que restan simplemente multiplicando por 1,2 (12/10).

\subsection{La movilidad intramunicipal en los distintos censos}

Es imprescindible contar los movimientos internos en cada municipio para poder hablar del conjunto de la movilidad residencial intrametropolitana, que está compuesta de cambios entre municipios e internos a los municipios. Si los primeros están contados de la misma forma en los tres censos sucesivos (utilizando la pregunta sobre el lugar de residencia con ocasión del censo anterior), los segundos no. Las formas en que se pregunta por los cambios de vivienda han variado entre censos:

— En 1991 se pregunta de forma idéntica sobre cambios de domicilio y de municipio. En la cuestión acerca del lugar de residencia en 1981, se incluyeron dos opciones a este respecto: en el mismo municipio y en el mismo domicilio y residía en el mismo municipio, en otro domicilio 5 . Sin duda, es la mejor forma de recoger información cuando se quiere estudiar la movilidad residencial compuesta de cambios de municipio y de cambios de vivienda dentro del municipio, dado que ambos están medidos de la misma forma.

- En 2001, hay que separar los que vivían en 1991 en el mismo municipio en dos grupos, según el año desde el que residen en la vivienda los miembros del hogar, pero en caso de que no llegaran todos a la vez a la vivienda, se refiere al primero que lo hizo. Seguramente es, a nuestros efectos, la peor de las formas de referirse a la movilidad intramunicipal, porque la base de cálculo no reside en los cambios individuales.

- En 2011, hay que separar los que vivían en 2001 en el mismo municipio en dos grupos según el año de llegada a la vivienda de cada individuo. Aquí la base de cálculo sí es individual, pero los cambios de municipio y el resto de cambios de vivienda se cuentan de forma diferente.

El problema de que los movimientos intramunicipales no estén contados de la misma forma complica las comparaciones a lo largo del tiempo, aunque no supon-

5. No obstante, en las tablas prediseñadas por el INE, solo están tabulados los cambios que suponen migraciones, no los de domicilio, para lo que hay que acudir a la aplicación que permite diseñar las tablas o a los microdatos. 
Figura 4. Preguntas censales para estimar los cambios intramunicipales en los tres censos
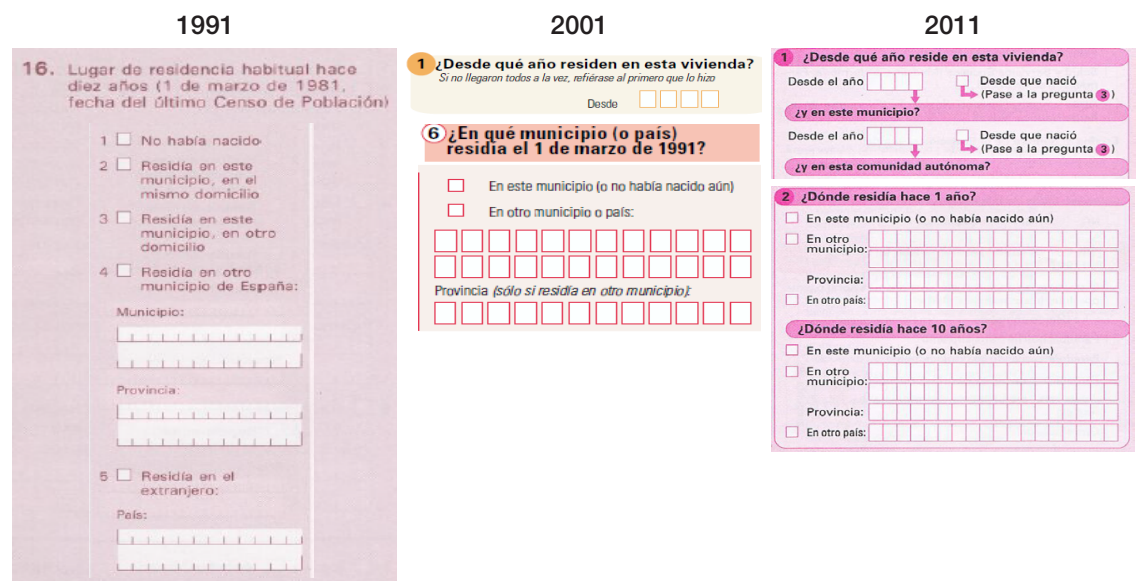

Fuente: cuestionarios censales, www.ine.es

ga problemas si comparamos distintos ámbitos territoriales en un solo momento censal. Tomando como referencia el sistema de 2011, puede estimarse lo siguiente:

- El procedimiento de 2011 tiende a sobreestimar los movimientos en comparación con el de 1991. La razón es que quienes viven en la misma vivienda en el censo anterior, después hayan salido y después hayan vuelto, aparecen como inmóviles en el de 1991, mientras que serían móviles en el último.

- El procedimiento de 2001 también subestima los movimientos en comparación con el de 2011. La razón es que se consideran inmóviles en el periodo de referencia todos aquellos que, viviendo en el mismo municipio, en el momento del censo, habitan una vivienda que ya antes estaba ocupada por algún miembro del hogar. Es decir, todas las personas que van a convivir en un hogar preexistente.

- Según esto, en comparación con el procedimiento de 2011, el de 2001 subestima los movimientos aún más que el de 1991.

Podemos calcular, para el censo de 2011, la movilidad siguiendo el procedimiento del censo de 2001. Dado que, en el de 2011, tenemos la llegada a la vivienda de todos los miembros del hogar, podemos calcular cuántos llegaron entre 2002 y 2011 a un domicilio ya existente a 1 de enero de $2002^{6}$. Esto solo se puede hacer con los microdatos censales que son de libre acceso público.

En el cuadro 5, se resumen estos cálculos para los cambios producidos en toda España. Los que se trasladan de lugar de residencia instalándose en un

6. La razón de que haya que hacerlo en esa fecha es que solo se preguntaba por el año de llegada, no por el mes, lo que significa que consideramos como anteriores a la fecha censal las llegadas producidas durante los meses de noviembre y diciembre de 2001. 
Cuadro 5. Cambios de lugar de residencia en función del año de llegada del primer miembro del hogar a la vivienda, según el censo de 2011 en España

\begin{tabular}{|c|c|c|c|c|}
\hline Lugar de residencia diez años antes & $\begin{array}{l}\text { (1) Hogares } \\
\text { preexistentes } \\
\text { a } 1-1-2002\end{array}$ & $\begin{array}{l}\text { (2) Hogares } \\
\text { posteriores } \\
\text { a 1-1-2002 }\end{array}$ & (3) Total & $\begin{array}{l}\text { Razón } \\
\text { (3) / (2) }\end{array}$ \\
\hline Mismo municipio, sin cambio de vivienda & 24.497 .837 & 0 & 24.497.837 & \\
\hline Mismo municipio, con cambio de vivienda & 924.307 & 7.208 .186 & 8.132 .493 & 113 \\
\hline Distinto municipio, misma provincia & 416.299 & 3.152 .181 & 3.568 .480 & 113 \\
\hline Distinta provincia, misma comunidad & 55.969 & 403.617 & 459.586 & 114 \\
\hline Distinta comunidad & 206.046 & 1.424 .780 & 1.630 .826 & 114 \\
\hline Extranjero & 325.422 & 3.092 .746 & 3.418 .168 & 111 \\
\hline No había nacido & 1.655 .651 & 3.211 .685 & 4.867 .336 & 152 \\
\hline Total & 28.081 .531 & 18.493.195 & 46.574 .726 & \\
\hline
\end{tabular}

Fuente: elaboración propia a partir de los microdatos del censo de 2011.

hogar que ocupaba la vivienda con anterioridad al 1 de enero de 2002 son 3.583 .688 (28.081.531 - 24.497.838), de los que más de millón y medio no había nacido, aproximadamente un millón son migrantes y cerca de otro millón se mueven dentro del mismo municipio.

La cifra de 7.208.186 es la que obtendríamos con el procedimiento de cálculo del censo de 2001, frente a la cifra de 8.132.493, que es la que tenemos con el procedimiento de 2011. Por tanto, este último da 113 móviles por cada 100 de aquel. Es decir, las personas que llegan a hogares ya constituidos son 13 por cada 100 que ocupan la vivienda con posterioridad a 2001. Obsérvese que los migrantes llegados de otros municipios o del extranjero a hogares constituidos antes de 2001 lo hacen en proporciones parecidas; excepto en el caso de los que no habían nacido, que, como era de esperar puesto que todos ellos llegan a hogares ya constituidos, suponen una razón mucho mayor.

Por tanto, para comparar de forma más aproximada las cifras de los censos de 2001 y 2011, habría que corregir el número de cambios en uno u otro censo. Bien eliminando de la cifra del censo de 2011 los cambios de individuos que llegan a hogares que ya existían en 2001, bien estimando mayor número de móviles intramunicipales en el censo de 2001. La primera opción tiene la ventaja de que ofrece cifras que son más comparables con las del censo de 1991, puesto que este también subestima los cambios en relación con el procedimiento de 2011, pero deja como principal criterio de estimación el procedimiento de 2001, que, como ya se dijo, es el peor. La segunda opción presenta la ventaja de tomar como referencia un mejor criterio, el de 2011, pero exige corregir también la cifra del censo de 1991, que está claramente subestimada.

No podemos hacer algo parecido con las cifras del censo de 1991, pues no se preguntó por el año de llegada a la vivienda de ninguna forma. No obstante, un 4,9\% de quienes afirman vivir en el mismo municipio que en 1981 había llegado al mismo con posterioridad a ese año y, por consiguiente, también a la vivienda. Según el procedimiento del censo de 2011, esta población apare- 
Cuadro 6. Número original y corregido de personas que cambian de vivienda y que residían en el mismo municipio en la fecha del censo anterior, en los censos de 1991, 2001 y 2011

\begin{tabular}{lcrr}
\hline & \multicolumn{2}{c}{ Mismo municipio, distinto domicilio } \\
\cline { 2 - 4 } & & \multicolumn{2}{c}{ Cifras corregidas } \\
\cline { 2 - 4 } & Cifras originales & Método 2001 & Método 2011 \\
\hline Censo de 1991 (1) & 7.041 .012 & & 7.386 .022 \\
Censo de 2001 (2) (corregido a 10 años) & 9.686 .703 & 9.376 .729 & 10.579 .108 \\
Censo de 2011 (3) & 8.132 .493 & 7.208 .186 & 8.132 .493 \\
Variación (2) / (1) & $34 \%$ & & $44 \%$ \\
Variación (3) / (2) & $-14 \%$ & $-23 \%$ & $-23 \%$ \\
\hline
\end{tabular}

Fuente: elaboración propia

cería como móvil intramunicipal. Desgraciadamente, no podemos hacer un cálculo parecido para quienes, viviendo en el mismo municipio y en el mismo domicilio, hayan vuelto a él tras haber vivido fuera a lo largo de esos diez años. Obviando esto último, hay que incrementar la cifra de móviles intramunicipales, al menos en aquel porcentaje para reducir el error en la comparación con los otros censos.

Las estimaciones resultantes para el total de móviles intramunicipales en la población española se recogen en el cuadro 6 junto a las cifras originales, aunque la corrección de la cifra del censo de 1991 es imprecisa.

La corrección de las cifras referidas a la movilidad en el año inmediatamente anterior a las fechas de realización del censo es más sencilla, pero tampoco está exenta de dificultades. Además de lo ya dicho al final del apartado anterior sobre el periodo de referencia de los datos, en el censo de 2001, siguiendo el mismo procedimiento explicado para la movilidad a diez años, es necesario multiplicar el número de movimientos intramunicipales por 1,32 (cifra que incluye la reestimación del periodo y de los cambios de vivienda a hogares ya preexistentes).

\section{Evolución de la movilidad residencial y migratoria}

Al aplicar las correcciones propuestas, referidas al periodo y la movilidad intramunicipal, obtenemos las cifras de evolución de la movilidad residencial y migratoria española recogidas en el cuadro 7. Las cifras estimadas se han redondeado al millar, para poder distinguirlas de las cifras directamente obtenidas de los censos. Las de 2011 están redondeadas a 5 unidades por el propio INE, dada la naturaleza muestral del censo.

La movilidad residencial y migratoria interior en España aumenta casi un 24\% entre los dos primeros censos, que recogen las décadas de 1980 y 1990, mientras disminuye ligeramente en el primer decenio del siglo XXI. Pero eso ocurre por una evolución muy desigual del número de móviles intramunicipales frente a los intermunicipales (las migraciones estadísticas), pues las pri- 
Cuadro 7. Evolución de la movilidad residencial y migratoria en España, original del censo de 2011 y reestimada para los censos de 2001 y 1991, para periodos de diez años

\begin{tabular}{lrrrrr}
\hline & \multicolumn{1}{c}{1991} & \multicolumn{1}{c}{2001} & \multicolumn{1}{c}{2011} & $2001-1991$ & $2011-2001$ \\
\hline Movilidad intramunicipal & 7.386 .000 & 10.579 .000 & 8.132 .495 & $43 \%$ & $-23 \%$ \\
Movilidad intermunicipal & 3.610 .431 & 3.679 .000 & 5.658 .890 & $2 \%$ & $54 \%$ \\
Total mov. residencial y migratoria & 10.996 .000 & 14.258 .000 & 13.791 .385 & $30 \%$ & $-3 \%$ \\
Inmigración del extranjero & 403.390 & 947.000 & 3.418 .170 & $135 \%$ & $261 \%$ \\
\hline
\end{tabular}

Nota: las cifras estimadas están redondeadas al millar.

Fuente: elaboración propia a partir de explotaciones específicas de los censos de 1991, 2001 y 2011.

meras alcanzan un extraordinario volumen en los años noventa para después caer abruptamente, y las segundas se mantienen en los dos primeros periodos para luego elevarse más de un $50 \%$. Además, la inmigración proveniente del extranjero estuvo cerca de cuadriplicarse.

El descenso de la movilidad intramunicipal puede estar ligado al cambio en el ciclo inmobiliario en el país. Desde finales de la década de 1990 y a lo largo de la primera parte del periodo 2001-2011, se vivió un enorme impulso en la compraventa de viviendas que se detuvo bruscamente en 2007, con lo que los últimos años del periodo fueron de baja movilidad frente al decenio anterior, en que fue alta. Esta podría ser la razón de dicha evolución tan peculiar cuando se comparan estos tres periodos, pero que no puede entenderse sin el concurso de la movilidad intermunicipal, especialmente metropolitana.

Para medir la evolución de la movilidad residencial metropolitana, tenemos dos opciones. Una es considerar la propia evolución del universo metropolitano, que significa aparición de nuevas áreas y cambios en los ámbitos que comprenden entre unos censos y otros. La segunda es considerar el mismo universo metropolitano, el de 2011, a lo largo del periodo de treinta años estudiado. Esta última es la opción elegida, por lo que obtenemos lo que ha ocurrido dentro de los mismos espacios, como si las áreas no hubiesen cambiado en extensión ni en número y fuesen las de 2011.

Como sabemos, la movilidad residencial metropolitana incluye cualquier tipo de cambio de domicilio entre las fechas consideradas, ya sean internos al municipio o entre municipios del área. Pero, en el cuadro 8, se incluyen, además, los movimientos con origen o destino fuera de las áreas, y los movimientos entre unas y otras áreas, es decir, intermetropolitanos, que son migraciones, pero no movilidad residencial. Por último, aparece la inmigración internacional con destino a las áreas metropolitanas. En este cuadro, el universo metropolitano español aparece como un todo, pero se ha obtenido a partir de la evolución de cada una de las 44 áreas existentes en 2011.

Del cuadro 8 , se deduce que la evolución de la movilidad intramunicipal metropolitana fue prácticamente igual que en el conjunto de España (cuadro 7); aunque hay que tener en cuenta que el universo metropolitano representa más de dos terceras partes de la población española. Sin embargo, la 
Cuadro 8. Movilidad residencial metropolitana y migratoria con el exterior, con las cifras corregidas de los censos de 1991, 2001 y 2011, para periodos de diez años

\begin{tabular}{|c|c|c|c|c|c|}
\hline & 1991 & 2001 & 2011 & 2001-1991 & 2011-2001 \\
\hline Movilidad intramunicipal & 5.194 .000 & 7.391 .000 & 5.809 .338 & $42 \%$ & $-21 \%$ \\
\hline Movilidad intermunicipal & 1.317 .254 & 1.752 .000 & 2.577 .755 & $33 \%$ & $47 \%$ \\
\hline Total movilidad residencial metropolitana & 6.511 .000 & 9.144 .000 & 8.387 .093 & $40 \%$ & $-8 \%$ \\
\hline Inmigración del resto de España & 602.119 & 443.000 & 723.387 & $-26 \%$ & $63 \%$ \\
\hline Emigración al resto de España & 481.426 & 475.000 & 741.034 & $-1 \%$ & $56 \%$ \\
\hline Migración intermetropolitana & 667.431 & 564.000 & 904.113 & $-15 \%$ & $60 \%$ \\
\hline Saldo con el resto de España & 120.693 & -32.000 & -17.647 & $-127 \%$ & $-45 \%$ \\
\hline Inmigración del extranjero & 275.908 & 682.000 & 2.433 .863 & $147 \%$ & $257 \%$ \\
\hline
\end{tabular}

Nota: las cifras estimadas están redondeadas al millar.

Fuente: elaboración propia a partir de explotaciones específicas de los censos de 1991, 2001 y 2011.

movilidad residencial intermunicipal metropolitana creció en ambos periodos, prueba evidente de que el proceso de desarrollo del fenómeno metropolitano se incrementó, sobre todo en la última década. Los datos parecen indicar que esta generalización y profundización del proceso se produjo ya en el siglo XXI, tras un periodo en que la movilidad intramunicipal creció mucho. Aunque no aparece en el cuadro, podemos decir que uno de los tipos de flujos que más creció fue el que afecta a los distintos municipios de las coronas metropolitanas entre sí, lo que muestra la progresiva integración de estos municipios en este proceso.

En el último decenio, se incrementaron todas las formas de migraciones. Aumentaron tanto los flujos de salida de las áreas metropolitanas como los de entrada, especialmente los provenientes del extranjero, pero también los intermetropolitanos. De entre las migraciones interiores, las más abundantes son estas últimas, las que tienen lugar entre distintas áreas como origen y destino: son migraciones plenamente interurbanas.

La movilidad residencial metropolitana puede ser considerada, también, en términos relativos, como una proporción de las personas móviles en el periodo respecto al total de personas susceptibles de haberse movido ${ }^{7}$.

La movilidad intermunicipal metropolitana no dejó de crecer en términos relativos, mientras que la intramunicipal descendió en el último periodo tras el enorme crecimiento en la década anterior (figura 5). Todo parece indicar que, además del parón en la movilidad provocado por la crisis económica que empezó en 2007, hay un proceso de sustitución de movilidad de corta distancia por otra más larga y metropolitana.

7. Para ello, se ha de tomar como denominador las personas que residían en las respectivas áreas, tanto al final como también al principio de cada periodo, por lo que hay que descartar a los inmigrantes provenientes del exterior de las áreas y, por supuesto, a quienes en la fecha del censo anterior no habían nacido, puesto que todas estas cifras se basan en una pregunta sobre el lugar de residencia en el momento estudiado. 
Figura 5. Proporción de móviles metropolitanos, por cada mil habitantes, diferenciando entre intermunicipal e intramunicipal en tres censos sucesivos

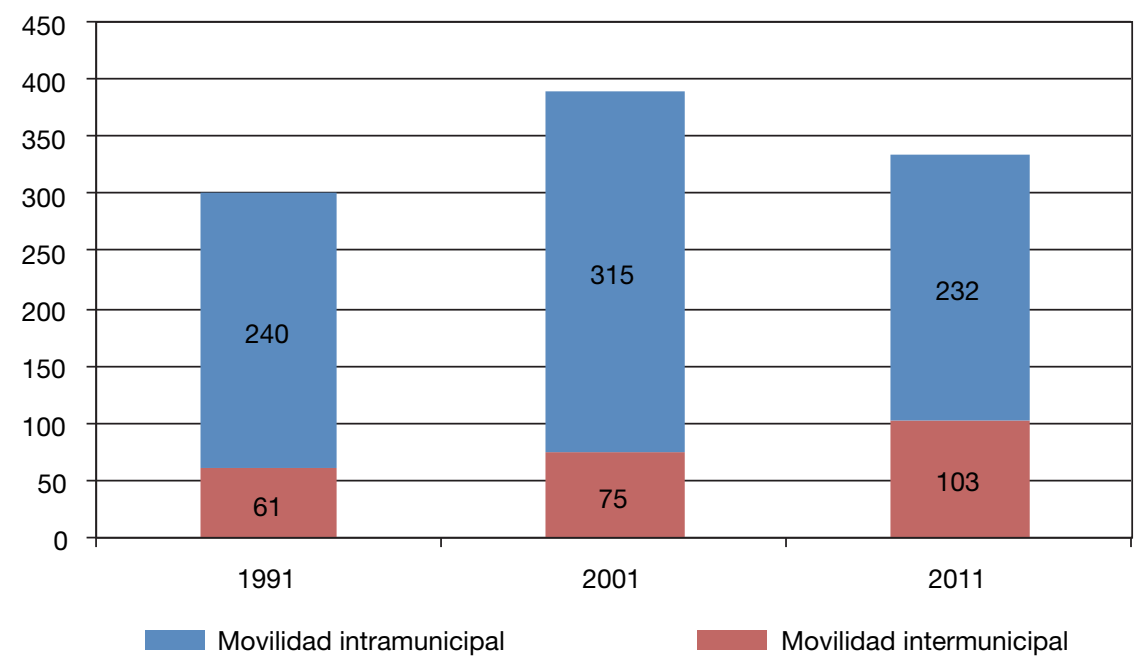

Fuente: elaboración propia a partir de explotaciones específicas de los censos de 1991, 2001 y 2011.

\section{Observaciones finales}

Pensamos que la definición restringida de movilidad residencial, que engloba los cambios de vivienda intramunicipales y los que se producen entre municipios dentro de cada una de las áreas metropolitanas, es preferible a la definición amplia, que incluye además todo tipo de migraciones. La falta de un significado consolidado - tan frecuente, por otra parte, en muchos conceptos utilizados en ciencias sociales - está estrechamente ligada a su delicada distinción del vecino concepto de migración, más por razones empíricas que teóricas. Aunque la literatura existente, como ya hemos visto, ha encontrado motivos y determinantes diferentes en ambos tipos de movilidad.

Para poder estudiar la evolución de la movilidad residencial metropolitana, es necesario corregir las cifras de algunos de los censos. Si tomamos como referencia el último, aunque no sea el que mejor la mida, hemos de revisar sobre todo las cifras del censo de 2001. A modo de síntesis, los factores de corrección propuestos se incluyen en el cuadro 9. Como puede observarse, las diferencias entre unos ámbitos y otros son pequeñas (inexistente en el periodo, puesto que se trata del mismo cualquiera que sea el ámbito), por lo que, para algunos estudios, podría adoptarse un factor único para todos ellos. No obstante, las diferencias son mayores (entre 1,07 y 1,23 de hogares) cuando se calculan para cada una de las áreas metropolitanas ${ }^{8}$.

8. Las cifras y las proporciones de movilidad de todas las áreas pueden consultarse en http:// www.movitra.tita.geographica.gs/es/ 
Cuadro 9. Factores de corrección propuestos para la movilidad intramunicipal

\begin{tabular}{lcccc}
\hline & & \multicolumn{3}{c}{ Censo de 2001 } \\
\cline { 3 - 5 } & Censo de 1991 & Del periodo & De hogares & Total \\
\cline { 2 - 5 } Total de España & 1,049 & 0,968 & 1,128 & 1,092 \\
Total áreas metropolitanas & 1,052 & 0,968 & 1,126 & 1,090 \\
\hline
\end{tabular}

Fuente: elaboración propia.

Sin embargo, aunque en estudios que utilizan cifras agregadas podamos hacer estas reestimaciones, en los estudios basados en registros individuales (a partir de microdatos censales), no podemos hacerlo sino parcialmente. Si trabajamos con individuos, sabemos si se habrían desplazado o no con arreglo a las preguntas formuladas en cada censo, pero no respecto a las preguntas de otros censos, excepto en el caso del censo de 2011, porque podemos descontar los móviles que llegaron a viviendas no habitadas, agregándoles el año de llegada del hogar, tal como viene recogido en el procedimiento de 2001. Es la única forma de asegurar que estamos analizando el mismo fenómeno o, por lo menos, que estamos reduciendo los posibles errores al comparar entre ambos censos. Por eso, también para estudiar la movilidad con microdatos, hay que corregir antes de poder comparar entre censos, aunque esas correcciones sean más limitadas.

También conviene insistir en el efecto de "deformación» del tiempo que ejercen las preguntas sobre el último cambio; por ejemplo: si estudiamos la movilidad de propietarios e inquilinos de viviendas, dado que estos últimos tienen un perfil más móvil, van a acumularse al final del periodo frente a una distribución en el tiempo algo más uniforme de los que viven en propiedad. Así que esto no solo afecta al cálculo de tasas agregadas de movilidad, sino a cualquier estudio que use expresamente la variable del año de llegada a la vivienda o al municipio.

A lo largo de los treinta años analizados, la movilidad metropolitana siguió pautas evolutivas parecidas a las generales de movilidad residencial y migratoria en España. Pero la evolución experimentó un gran aumento en los años noventa, seguido de un descenso en la siguiente década. Esto se debió, sobre todo, a la peculiar evolución de la movilidad residencial intramunicipal.

Esta evolución admite dos explicaciones no necesariamente incompatibles. Una, que el efecto de la crisis en la movilidad residencial del 2007 al 2011 es enorme, tal como se puede ver en los datos censales por año de llegada al municipio presentados en las figuras 2 y 3 . Otra, que la movilidad metropolitana ha ido cambiando a lo largo de las tres décadas, de forma que, en el proceso de metropolitanización de las áreas más incipientes, se pase por una etapa intermedia de mayor importancia relativa de los movimientos internos (además del incremento absoluto). Pero esta hipótesis requiere de un análisis por áreas pormenorizado y, en todo caso, no explica la misma figura evolutiva en la España no metropolitana.

En todo caso, las tendencias se vieron afectadas por la crisis. Aunque puede apreciarse al comparar la movilidad en los tres periodos íntercensales, se podría 
ver mejor si solo tomamos los tres años en que se hicieron los censos. La razón es que los periodos intercensales muestran tendencias más estructurales y menos afectadas por los cambios coyunturales, mejores para analizar cómo afecta a la movilidad residencial el desarrollo en el largo plazo del fenómeno metropolitano9. Y es así porque no es posible cuantificar el efecto de la crisis, al no poder descomponer esa movilidad por años, dentro del periodo íntercensal, por la grave deformación del tiempo que imponen las preguntas censales. Pero algo se puede intuir y estimar, si se considera que la crisis supone una ruptura en una tendencia que podría haber continuado si no hubiera tenido lugar.

A pesar de todos los problemas planteados y de las precauciones a tomar en la interpretación de los datos, los censos son la fuente más completa, fiable y con mayor grado de desagregación territorial para analizar la movilidad residencial y migratoria. Desgraciadamente, tienen limitaciones difíciles de sortear. Pero, desde el punto de vista metodológico, a veces es mejor mantener las mismas preguntas en censos sucesivos que cambiarlas en cada uno de ellos buscando mejorar las preguntas. Si esto último es necesario, hay que formular dobles preguntas que permitan comparar las estimaciones de la variable investigada con el antiguo y el nuevo método. Esto es posible entre 2001 y 2011, con dificultades, pero no con el censo de 1991. No obstante, la del censo de 1991 parece la mejor pregunta para analizar el fenómeno aquí investigado. En cualquier caso, esta recomendación puede resultar superflua, dado que todo parece indicar que los próximos censos se basarán completamente en registros administrativos, con lo que estos desaparecerán en la forma en que los hemos conocido hasta ahora.

\section{Referencias bibliográficas}

Alonso, William (1960). «A theory of the urban land market». Papers and Proceedings of the Regional Science Association [en línea], 6 (1), 149-158. <https://doi.org/10.1111/j.1435-5597.1960.tb01710.x>.

Aragonés TAPIA, Juan Ignacio y Amérigo Cuervo-ARANGo, María (1987). «Movilidad residencial en la ciudad: Factores determinantes y consecuencias». Estudios Sobre Consumo, 11 (7), 122-135.

Arévalo Tomé, Raquel; Ferrero Martínez, Loly; Otero Giráldez, María Soledad y UÑa ÁlVAREZ, Jacobo (2008). «Movilidad residencial en España: Un análisis longitudinal». Documentos de Traballo do Departamento de Economía Aplicada, 3.

AUDES (2016). Áreas urbanas de España [en línea]. <http://alarcos.esi.uclm.es/per/ fruiz/audes/index.htm> [Consulta: 25 enero 2017].

BAYONA-I-CARRASCO, Jordi y PUJADAS-I-RÚBIES, Isabel (2010). «Cambios residenciales internos en la ciudad de Barcelona: Evolución y características territoriales». Investigaciones Geográficas [en línea], (52), 9-36.

$<$ https://doi.org/10.14198/ingeo2010.52.01>.

9. Es decir, para un análisis interno de la evolución del fenómeno metropolitano, ya que la pregunta analizada excluye la inmigración y la emigración de las áreas desde el censo anterior y la movilidad interna de los inmigrantes en ese periodo. 
- (2014). «Movilidad residencial y redistribución de la población metropolitana: Los casos de Madrid y Barcelona». EURE [en línea], 40 (119), 261-287. $<$ https://doi.org/10.4067/s0250-71612014000100012>.

Berman, Yitzhak y EAGLSTEIN, Salomon (1988). "Country of Origin and Socioeconomic Level as Changing Predictors of Juvenile Delinquency». Journal of Ethnic Studies, 16 (2), 137-142.

Brown, Lawrence A.; Moore, Eric G. (1970). «The Intra-urban Migration Process: A Perspective». Geografiska Annaler [en línea], series B, 52 (1), 1-13. <https://doi.org/10.2307/490436>.

BuRNLEY, Ian Harry (1996). «Associations between Overseas, Intra-Urban and Internal Migration Dynamics in Sydney, 1976-91». Journal of the Australian Population Association [en línea], 13 (1). <https://doi.org/10.1007/bf03029321>.

Cadwallader, Martin (1992). Migration and Residential Mobility: Macro and micro approaches. Madison: University of Wisconsin Press.

CASADO-DíAZ, José Manuel (2000). Trabajo y territorio: Los mercados laborales locales de la Comunidad Valenciana. Alicante: Publicaciones de la Universidad de Alicante.

ClarK, William A.V. (1982). «Recent research on migration and mobility: A review and interpretation». Progress in Planning [en línea], 18 (1), 1-56. <https://doi.org/10.1016/0305-9006(82)90002-2>.

- (2013). "Life Course Events and Residential Change: Unpacking Age Effects on the Probability of Moving». Journal of Population Research [en línea], 30 (4), 319-334. <https://doi.org/10.1007/s12546-013-9116-y>.

Clark, William A.V.; Deurloo, Marinus C. y Dieleman, Frans (2006). «Residential Mobility and Neighbourhood Outcomes». Housing Studies [en línea], 21 (3), 323-342. <https://doi.org/10.1080/02673030600585946>.

Clark, William A.V.; Duque Calvache, Ricardo y Palomares-Linares, Isabel (2015). «Place Attachment and the Decision to Stay in the Neighbourhood». Population, Space and Place [en línea]. <https://doi.org/10.1002/psp.2001>.

Clark, William A.V. y Huang, Yoaquin (2003). "The Life Course and Residential Mobility in British Housing Markets». Environment and Planning A [en línea], 35, 323-339. $<$ https://doi.org/10.1068/a3542>.

Clark, William A.V. y Onaka, Jun L. (1983). «Life Cycle and Housing Adjustment as Explanations of Residential Mobility». Urban Studies [en línea], 20 (1), 47-57. <https://doi.org/10.1080/00420988320080041>.

Courgeau, Daniel (1988). «Méthodes de mesure de la mobilité spatiale: Migrations internes, mobilité temporaire et navettes». Population, 43 (4), 877-880.

Courgeau, Daniel y Meron, Monique (1995). «Mobilité résidentielle, activité et vie familiale des couples». Économie et Statistique, Programme National Persée [en línea], 290 (1), 17-31. <https://doi.org/10.3406/estat.1995.6016>.

DEBRAND, Thierry y TAFFIN, Claude (2005). «Les facteurs structurels et conjoncturels de la mobilité résidentielle depuis 20 ans». Economie et Statistique [en línea], 381, $125-146$. <https://doi.org/10.3406/estat.2005.7211>. 
De ESTEBAN, Alfonso (1981). Las áreas metropolitanas en España: un análisis ecológico. Madrid: Centro de Investigaciones Sociológicas. Demopaedia: Diccionario demográfico multilingüe [en línea], 2017. <http://es-i.demopaedia.org> [Consulta: 25 enero 2017].

Dieleman, Frans M. (2001). «Modelling Residential Mobility: A Review of Recent Trends in Research». Journal of Housing and the Built Environment [en línea], 16 (3), 249-265. <https://doi.org/10.1023/A:1012515709292>.

Dieleman, Frans M.; Clark, William A.V. y Deurloo, Marinus C. (2000). «The Geography of Residential Turnover in Twenty-seven Large US Metropolitan Housing Markets, 1985-95». Urban Studies [en línea], 37 (2), 223-245. <https://doi.org/10.1080/0042098002168>.

DONZEAU, Nathalie y SHON, Jean-Louis Pan Ké (2009). «L'évolution de la mobilité résidentielle en France entre 1973 et 2006: Nouvelles estimations». Population [en línea], 64 (4), 779-795. <https://doi.org/10.3917/popu.904.0779>.

DuHAu, Emilio (2003). «División social del espacio metropolitano y movilidad residencial». Papeles de Población, 9 (36), 161-210.

Feria, José María (2004). «Problemas de definición de las áreas metropolitanas en España». Boletín de la Asociación de Geógrafos Españoles, 38, 85-100.

- (2008): «Un ensayo metodológico de definición de las áreas metropolitanas en España a partir de la variable residencia-trabajo». Investigaciones Geográficas [en línea], XIII, 46, 49-68. <https://doi.org/10.14198/ingeo2008.46.03>.

- (2010). «La delimitación y organización espacial de las áreas metropolitanas españolas: una perspectiva desde la movilidad residencia-trabajo». Ciudad y territorio. Estudios territoriales, 164, 189-210.

- (2015). Definición y pautas generales de dinámica y organización espacial. Áreas metropolitanas andaluzas. Sevilla: Consejería de Fomento y Vivienda. Junta de Andalucía. Universidad Pablo de Olavide. [en línea], <http://www.aopandalucia. es/inetfiles/resultados_IDI/GGI3001IDIV/entregable_parcial/Libro_A.pdf>

Feria, José María y MARTínez BERnABeú, Lucas (2016). «La definición y delimitación del sistema metropolitano español: Permanencias y cambios entre 2001 y 2011». Ciudad y Territorio: Estudios Territoriales, 187, 9-24.

FERnÁndeZ-Troyano, José Fernando (2010). «Movimientos de población en Andalucía y Cataluña (1995-2006): Una comparación desde la teoría de la modernización». Papers: Revista de Sociología [en línea], 95 (4), 1077-1103. $<$ https://doi.org/10.5565/rev/papers/v95n4.156>.

FuENTE, Ángel de la (2016). Series enlazadas de PIB y otros agregados de Contabilidad Nacional para España, 1955-2014 (RegDat_Nac versión 4.2) [en línea]. Estudios sobre la Economía Española - 2016/02. Fedea. <http://www.fedea.net/beta/datos/ index.html> [Consulta: 10 diciembre 2016].

García Coll, Arlinda; López Villanueva, Cristina y Pujadas, Isabel (2016). «Movilidad residencial en tiempos de crisis: ¿Una nueva relación entre centro y periferia? El caso de la región metropolitana de Barcelona». Scripta Nova, XX, 549 (4).

Geist, Claudia y MCManus, Patricia A. (2008). «Geographical mobility over the life course: Motivations and implications». Population, Space and Place [en línea], 14 (4), 283-303.

<https://doi.org/10.1002/psp.508>. 
GiBBS, Robert M. (1994). «The Information Effects of Origin on Migrants Job Search Behavior». Journal of Regional Science [en línea], 34 (2), 163-178. <https://doi.org/10.1111/j.1467-9787.1994.tb00861.x>.

GobiLlon, Laurent (2001). «Emploi, Logement et Mobilité Résidentielle». Economie et Statistique [en línea], 349, 77-98. $<$ https://doi.org/10.3406/estat.2001.7415>.

Halfacree, Keith; Flowerdew, Robin y Johnson, James H. (1992). «The characteristics of British migrants in the 1990s: Evidence from a new survey». Geographical Journal [en línea], 157-169. <https://doi.org/10.2307/3059785>.

Henley, Andrew (1998). «Residential mobility, housing equity and the labour market». The Economic Journal [en línea], 108 (447), 414-427. <https://doi.org/10.1111/1468-0297.00295>.

HowleY, Peter (2009). «Attitudes towards compact city living: Towards a greater understanding of residential behaviour». Land Use Policy [en línea], 26 (3), 792-798. <https://doi.org/10.1016/j.landusepol.2008.10.004>.

INE (2001). Proyecto censal: Censo de Población y Viviendas 2001 [en línea]. <http:// www.ine.es/censo2001/procen01.pdf>.

- (2011). Proyecto censal: Censo de Población y Viviendas 2011 [en línea]. <http:// www.ine.es/censos2011/censos2011_proyecto.pdf>.

- (2016). Indicadores urbanos [en línea]. <http://www.ine.es/prensa/np960.pdf>.

JiMÉNEZ BLASCO, Beatriz Cristina (1988). «Estructura espacial de las pautas de diferenciación residencial en la ciudad de Madrid». Anales de Geografía de la Universidad Complutense, 8, 139-151.

Jones, Colin; Leishman, Chris y Watkins, Craig (2004). «Intra-Urban Migration and Housing Submarkets: Theory and Evidence». Housing Studies [en línea], 19 (2), 269-283. <https://doi.org/10.1080/0267303032000168630>.

LONG, Larry; TUCKER, Jack C. y URTON, William L. (1988). «Migration distances: An international comparison». Demography [en línea], 25 (4), 633-640. <https://doi.org/10.2307/2061327>.

LÓPEZ GAY, Antonio (2003). "Intensidad y calendario de la movilidad residencial en la Unión Europea». Scripta Nova [en línea], 8, 157-180.

LÓPEZ GAY, Antonio y RECAÑO, Joaquín (2008). «La renovación sociodemográfica de un centro urbano maduro: Perfiles migratorios y filtros residenciales en la ciudad de Barcelona». Scripta Nova, 12, 126.

Ministerio de Fomento (2016). Atlas estadístico de las Áreas Urbanas. Metodología. <https://www.fomento.gob.es/NR/rdonlyres/30FB929E-009E-41E4-B020F2EDD37A9AB0/140255/metodologia_2016.pdf>. Atlas digital de las áreas urbanas. <http://atlasau.fomento.gob.es>.

Miralles Guasch, Carme; Donat, Carles y Barnada, Jaume (2007). «Habitatge i mobilitat residencial a la Regió Metropolitana i a la Província de Barcelona». Papers: Regió Metropolitana de Barcelona: Territori, Estratègies, Planejament, 46, 9-46.

Miralles Guasch, Carme y Tulla, Antoni F. (2012). "La región metropolitana de Barcelona: Dinámicas territoriales recientes». Boletín de la Asociación de Geógrafos Españoles, 58, 299-318.

MÓdEnes CABrerizo, Juan Antonio (1998). Flujos espaciales e itinerarios biográficos: La movilidad residencial en el área de Barcelona. Departamento de Geografía. Universidad Autónoma de Barcelona. Tesis doctoral. 
- (2000). «Movilidad residencial y dinámica familiar de los adultos jóvenes urbanos en los 80». Papers de Demografía, 170.

MuTH, Richard F. (1961). "The spatial structure of the housing market». Papers in Regional Science [en línea], 7 (1), 207-220. <https://doi.org/10.1111/j.1435-5597.1961.tb01780.x>.

NiedomysL, Thomas (2011). "How Migration Motives Change over Migration Distance: Evidence on Variation Across Socio-economic and Demographic Groups». Regional Studies [en línea], 45 (6), 843-855. <https://doi.org/10.1080/00343401003614266>.

NiedomysL, Thomas y Fransson, Urban (2014). "On distance and the spatial dimension in the definition of internal migration». Annals of the Association of American Geographers [en línea], 104 (2), 357-372. <https://doi.org/10.1080/00045608.2013.875809>.

PACIONE, Michael (2001). Urban Geography: A Global Perspective. Nueva York: Routledge.

PALOMARES-LinARES, Isabel (2014). «Cambios de vivienda y población anciana: Patrones y tendencias residenciales de las personas mayores en la realidad reciente». En: lópez Gay, A.; Rojo, F.; Solsona, M.; Andújar, A.; Cruz, J.; Iglesias, R.; FERIA, J.M. y VAHÍ, A. (eds). Cambio demográfico y socioterritorial en un contexto de crisis: XIV Congreso Nacional de Población [en línea], 529-541. Sevilla: Grupo de Población de la Asociación de Geógrafos Españoles. <http://www.agepoblacion. org/images/congresos/sevilla/DOC40.pdf>.

Quigley, John M. y WeInberG, Daniel H. (1977). «Intra-Urban Residential Mobility: A Review and Synthesis». International Regional Science Review [en línea], 2, 41-63. <https://doi.org/10.1177/016001767700200104>.

Roca Cladera, Josep; Moix Bergadà, Montserrat y Arellano Ramos, Blanca (2012). «El sistema urbano en España». Scripta Nova, XVI, 396.

Rossi, Peter H. (1955). Why families move: A study in the social psychology of urban residential mobility. Nueva York: Free Press of Glencoe.

SHON, Jean-Louis Pan Ké (2005). «Les sources de la mobilité résidentielle: Modifications intervenues sur les grandes sources de données dans l'étude des migrations». Documents de Travail, 127. París: INED.

SHORT, John R. (1978). "Residential mobility». Progress in Human Geography [en línea], 2 (3), 419-447. <https://doi.org/10.1177/030913257800200302>.

Smith, Terence R.; Clark, W.A.V.; Huff, James O. y Shupiro, Perry (1979). «A Decision-Making and Search Model for Intraurban Migration». Geographical Analysis [en línea], 11 (1), 1-22. <https://doi.org/10.1111/j.1538-4632.1979.tb00669.x>.

SusinO, Joaquín (2011). «La evolución de las migraciones interiores en España: Una evaluación de las fuentes demográficas disponibles». Papers [en línea], 96 (3), 853-881. $<$ https://doi.org/10.5565/rev/papers/v96n3.304>.

- (2003). Movilidad residencial: Procesos demográficos, estrategias familiares y estructura social [en línea]. Granada: Universidad de Granada. Tesis doctoral. <http://hdl. handle.net/10481/36716>.

Susino, Joaquín y PALOMARES-LinARES, María Isabel (2013). «La movilidad residencial en el área metropolitana de Granada». En: CAMACHO BALleSTA, José Antonio y Jiménez Olivencia, Yolanda (eds.). Desarrollo Regional Sostenible en tiempos de crisis, 2, 345-363. Granada: Universidad de Granada. 
Tolbert, Charles M.; Blanchard, Troy C. e Irwin, Michael D. (2009). «Measuring migration: Profiling residential mobility across two decades». Journal of Applied Social Science [en línea], 3 (2), 24-38. <https://doi.org/10.1177/193672440900300203>.

U.S. Census Bureau (2003). Geographical Mobility: 1995 to 2000. Census 2000 Brief C2KBR-28. Washington, D.C.: U.S. Department of Commerce, Economics and Statistics Administration.

UISSP (1985). Diccionario demográfico multilingüe. Lieja: Ordina.

WeINBERG, Daniel H. (1979). «The Determinants of Intra-Urban Household Mobility». Regional Science and Urban Economics [en línea], 9, 219-246. <https://doi.org/10.1016/0166-0462(79)90014-0>.

White, Michael J. y Mueser, Peter R. (1988). «Implications of boundary choice for the measurement of residential mobility». Demography [en línea], 25 (3), 443-459. <https://doi.org/10.2307/2061543>.

WU, Weiping (2006). "Migrant Intra-urban Residential Mobility in Urban China». Housing Studies [en línea], 21 (5), 745-765. <https://doi.org/10.1080/02673030600807506>.

Zamora, Francisco y Serrano, Pedro (2000). "Migraciones y cambios de vivienda». En: Taltavull, Paloma (coord.). Vivienda y familia, 385-413. Madrid: Fundación Argentaria / Visor.

ZaX, Jeffrey. S. (1994). "When is a move a migration?». Regional Science and Urban Economics, 24 (3), 341-360.

ZaX, Jeffrey S. y KaIN, John F. (1991). "Commutes, quits and moves». Journal of Urban Economics [en línea], 29 (1), 153-155.

<https://doi.org/10.1016/0094-1190(91)90010-5>. 